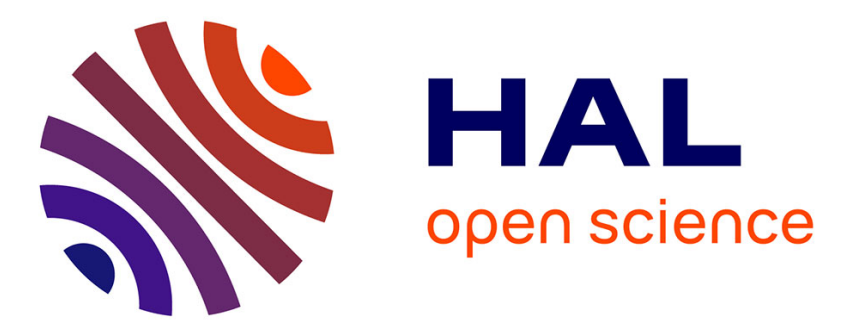

\title{
A new washing procedure for inorganic element analysis of hair
}

Dominique Verrey, Séverine Durand, Olivier Thomas, Vanessa Lelévrier, Philippe Quénel, Barbara Le Bot

\section{> To cite this version:}

Dominique Verrey, Séverine Durand, Olivier Thomas, Vanessa Lelévrier, Philippe Quénel, et al.. A new washing procedure for inorganic element analysis of hair. Journal of Exposure Science and Environmental Epidemiology, 2019, 29 (5), pp.706-717. 10.1038/s41370-018-0112-3 . hal-02020708

\section{HAL Id: hal-02020708 \\ https://hal-univ-rennes1.archives-ouvertes.fr/hal-02020708}

Submitted on 6 Jan 2020

HAL is a multi-disciplinary open access archive for the deposit and dissemination of scientific research documents, whether they are published or not. The documents may come from teaching and research institutions in France or abroad, or from public or private research centers.
L'archive ouverte pluridisciplinaire HAL, est destinée au dépôt et à la diffusion de documents scientifiques de niveau recherche, publiés ou non, émanant des établissements d'enseignement et de recherche français ou étrangers, des laboratoires publics ou privés.

\section{(c)(1)}

Distributed under a Creative Commons Attribution| 4.0 International License 


\title{
A new washing procedure for inorganic element analysis of hair
}

\author{
Dominique Verrey ${ }^{1} \cdot$ Séverine Durand ${ }^{1} \cdot$ Olivier Thomas $^{1} \cdot$ Vanessa Lelévrier $^{1} \cdot$ Philippe Quénel $^{1} \cdot$ Barbara Le Bot $^{1}$
}

\begin{abstract}
Hair incorporates chemical compounds from the bloodstream and external sources as it grows. Different analytical procedures are proposed, but no consensus can be found for external contamination removal (washing stage). Thus, a major limitation of the use of hair analysis for human biomonitoring is the issue related to the washing efficiency, and the objective of this study was to propose a simple washing method for a better cleaning of external contamination. Based on a sequence of three steps of detergent or acid washing (Triton, nitric acid, and hydrochloric acid), the TNCl method was tested on raw and spiked samples and compared to other methods. Thirty-seven inorganic elements were analyzed by inductively Coupled Plasma Mass Spectrometry (ICP-MS) after washing and acid digestion of 10 hair samples (Li, Be, Na, Mg, Al, P, K, Ca, V, $\mathrm{Cr}, \mathrm{Fe}, \mathrm{Mn}, \mathrm{Co}, \mathrm{N}, \mathrm{Cu}, \mathrm{Zn}, \mathrm{As}, \mathrm{Se}, \mathrm{Sr}, \mathrm{Mo}, \mathrm{Ru}, \mathrm{Ag}, \mathrm{Cd}, \mathrm{Sn}, \mathrm{Sb}, \mathrm{Cs}, \mathrm{Ba}, \mathrm{La}, \mathrm{Ce}, \mathrm{Nd}, \mathrm{Gd}, \mathrm{Lu}, \mathrm{Tl}, \mathrm{Pb}, \mathrm{Bi}$, Th, and U). The inorganic element concentrations in the hair samples were compared to those reported in the literature. The TNCl method was shown to be more efficient than other methods based on the use of surfactants and organic solvents.
\end{abstract}

Keywords Washing method $\cdot$ Inorganics $\cdot$ Human exposure $\cdot$ ICP-MS $\cdot$ Hair analysis $\cdot$ Environmental contaminants

\section{Introduction}

Human beings are exposed to a wide range of chemicals through their environment, diet, and use of consumer products at home and/or in the workplace. This exposure to chemicals occurs through a variety of pathways and exposure routes, notably by inhalation and via dermal and oral uptake.

Human biomonitoring (HBM) has become an important tool for forensics, exposure assessment, and epidemiological studies. Indeed, HBM allows for the estimation of chemical exposure in the general population and/or specific groups, integrating all the different routes of exposure. Currently, urine, blood, and plasma [1] are extensively used as biological matrices for conducting HBM, yet the hair matrix is much less used for such a purpose. However, recent instrumental developments have provided typical use of this matrix for both organic and inorganic pollutants [2].

Hair incorporates chemical compounds from the bloodstream as it grows. These compounds have been detected

Barbara Le Bot

barbara.lebot@ehesp.fr

1 Univ Rennes, Inserm, EHESP, Irset (Institut de recherche en santé, environnement et travail) - UMR_S 1085, Rennes F-35043, France and quantified in various studies [3, 4], and hair appears to be a promising non-invasive matrix providing further information on a specific exposure window related to its length. However, one major limitation of the use of this matrix for HBM purposes is the issue related to our ability to remove exogenous contamination resulting from the external deposition of air, water, and dust in order to specifically measure endogenous contamination. Indeed, it is generally acknowledged that biologically incorporated molecules are located inside hair shafts (cortex and medulla), while the external contamination likely remains on the surface of hair scales (cuticle) [5]. To date, a major hurdle in the use of hair in biomonitoring is the decontamination or washing step of the external surface of hair [6].

Hair monitoring [7] has recently been applied to environmental [5], food [8], and occupational contaminants [9]. The techniques proposed for quantitative analysis of inorganics in hair including atomic absorption spectrometry (AAS) $[10,11]$, laser ablation inductively coupled plasma mass spectrometry (LA-ICP-MS) [12], ICP-optical emission spectrometry (ICP-OES) [13], and ICP-MS after mineralization $[14,15]$. All these techniques obtain similar results regarding certified materials. However, the concentrations of hair inorganic contaminants depend not only on the sample origin but also on the washing procedure, as a cleaning step is often carried out before the analysis. A recent review 
reported $\sim 50$ different washing procedures for hair inorganic analysis used in the last 10 years [16], and as stated by Kempson and Skinner [17], no consensus can be found.

The objective of the present study is to develop, test, and validate a whole analytical method for measuring 37 inorganic elements that includes a new simple washing step. The robustness of the method is evaluated using spiked samples, certified materials, interlaboratory trials, and real hair samples.

\section{Materials and methods}

\section{Chemicals and standards}

Solutions of $67 \%$ nitric acid and $34 \%$ hydrochloric acid (NORMATOM $^{\circledR}$ PROLABO) were provided by VWR International (Fontenay-sous-bois, France), as were EDTA, $25 \%$ ammonium hydroxide solution, and $31 \%$ hydrogen peroxide solution, both of quality Suprapur $^{\circledR}$ MERCK. Triton X-100 was purchased from Sigma-Aldrich (SaintLouis, USA), and acetone (PESTIPUR ${ }^{\circledR}$ ) was purchased from Carlo Erba (Val de Reuil, France). The standard solutions of each element at $1 \mathrm{~g} / \mathrm{L}$ in diluted nitric acid or hydrochloric acid were provided by Inorganic Ventures (Christiansburg, USA) or Techlab (Metz, France). Three certified solutions were used to control the calibration range: the standard reference material $1643 \mathrm{e}$, manufactured by the National Institute of Standards and Technology (NIST, Gaithersburg, USA), the 27 multielement custommade solution 507142, and the 5 multielement custommade solution 507143, the latter two of which were provided by Carlo Erba (Val de Reuil, France).

The gas for ICP-MS was purchased from Air Liquide (Paris, France): argon (purity $\geq 99.99 \%$ ), hydrogen (purity $\geq$ $99.99 \%$ ), and helium (purity $\geq 99.99 \%$ ) were of adequate quality for ICP analysis. Ultra-high quality (UHQ) water was produced in the lab with a Milli-Q gradient water purification system obtained from Millipore (Bedford, USA) with a resistivity of $18.2 \mathrm{M} \Omega / \mathrm{cm}$ at $25^{\circ} \mathrm{C}$.

Two certified materials of the elements in ground human hair were purchased from Analab or Promochem (Molsheim, France): certified reference material NCS ZC 81002b issued in 2005 approved by the China National Analysis Center for Iron and Steel (Beijing, China) and a reference material from the International Atomic Energy Agency (IAEA) IAEA-086 issued in 2000 (Vienna, Austria). These certified materials were commercialized and grounded to a powder form.

\section{Material}

A graphite block digestion system was manufactured by Environmental Express (Charleston, USA), and $15 \mathrm{~mL}$ polypropylene screw cap tubes (SC415) were purchased from Courtage Analyses Services (Mont-Saint-Aignan, France). In the laboratory, the tubes were cleaned using $1 \%$ nitric acid and dried prior to use. An Elmasonic S120 ultrasound bath was purchased from Grosseron (Couëron, France). A precision balance (MC210P) was provided by Sartorius (Göttingen, Germany).

An Agilent Technologies (Santa Clara, USA) 7500ce ICP-MS was used. The samples were handled using a CETAC (Waltham, USA) ASX-520 autosampler, a MicroFlow nebulizer, and a Scott nebulization chamber. The instrument was controlled by an HP Compaq 8000 computer and the Mass Hunter software.

\section{Hair samples and ethics}

Fourteen hair samples were collected from volunteers of our lab and stored in paper envelopes. The French Bioethics Law of 6 August 2004 [18] states that hair is excluded from ethics committee approval but needs informed consent (with parent's consent for children). The hair samples were stored at room temperature in plastic tubes. Ten hair samples (1-10) were collected for analysis, three samples (11-13) for a washing step test, and one (14) for a spiking test. Among the 14 samples, 10 came from men, and four came from children. The dominant color was brown (eight samples).

\section{Methodology}

The certified solutions, certified materials, and hair samples were analyzed under the same sequence. The certified solutions and the certified materials were used for calibration and mineralization checking, respectively. The certified solutions were directly analyzed with ICP-MS, while the certified materials and the hair samples were first mineralized. For each hair sample, a washing step was carried out before mineralization for part of the sample. The analysis of a raw (unwashed) hair sample provided information on the total contamination, and the analysis of a washed sample provided a proxy of the internal contamination (inorganics bound to the hair matrix). Figure 1 provides a schematic overview of the experimental approach to evaluating the performance of the new washing protocol.

\section{Washing}

Most of the washing methods found in the literature are based on procedures using mainly acetone or Triton X-100 [16] with washing stages varying from 1 to 7 [17]. For this study, three methods using three or five stages were considered based on their expected performances. The first one was the five-stage WAWAW (water-acetone-water-acetone-water) 


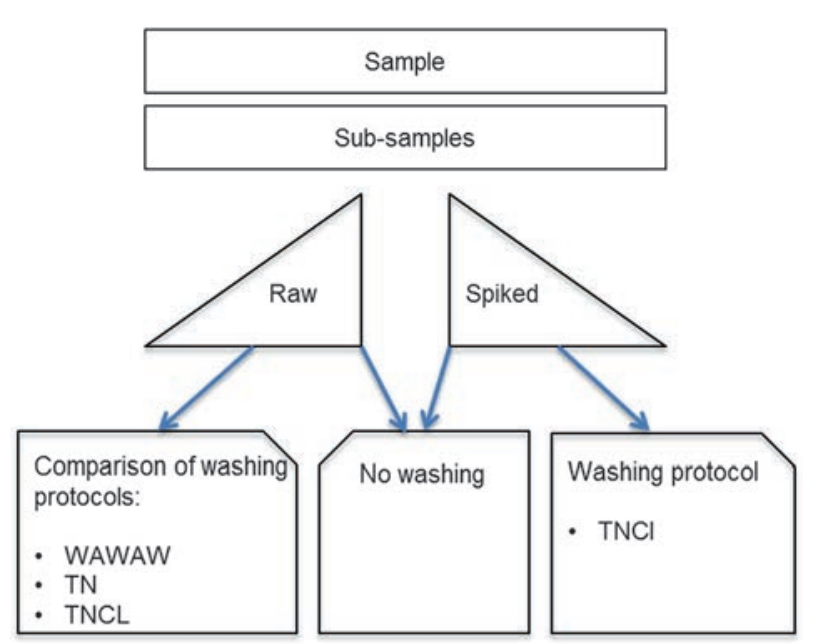

Mineralization (nitric acid, ultrasound bath, graphite oven)

ICP-MS analysis

Fig. 1 Schematic overview of the washing tests to evaluate the efficiency and repeatability of the new washing protocol

protocol (following a method suggested by Batista [19]), alternating water, acetone, water, acetone, and water with $10 \mathrm{~min}$ of contact time in an ultrasound bath at each step. Another method was the TN (Triton-nitric acid) washing protocol, proposed by Eastman [20], comprising five stages and alternating water, Triton, water, nitric acid, water, and water with $10 \mathrm{~min}$ of contact time in an ultrasound bath at each stage.

To improve the washing step, a new protocol was developed for this work. The TNCl protocol is a three-stage one, alternating Triton, nitric acid, and hydrochloric acid with 5 min of contact time in an ultrasound bath at each step. The three stages are as follows: the hair sample is placed in a tube of $50 \mathrm{~mL}$ in contact with $10 \mathrm{~mL} 0.5 \%$ Triton, followed by $10 \mathrm{~mL} 6.7 \%$ nitric acid and finally $10 \mathrm{~mL}$ $2 \%$ hydrochloric acid. All solutions were diluted in UHQ water. The concentration of nitric acid is the same as that in the TN protocol. At each stage, the sample solution was placed in the ultrasound bath for $5 \mathrm{~min}$, then drained and rinsed using UHQ water before the next step. At the end of each of the last step of the three methods (WAWAW, TN, and $\mathrm{TNCl}$ ), the sample was placed in a graphite oven and heated to $50^{\circ} \mathrm{C}$ until the hair was completely dry. A nonairtight lid was placed on the tube to limit airborne contamination. Finally, each hair sample was cut using ceramic scissors into segments of $2-5 \mathrm{~mm}$ and placed into a $50 \mathrm{~mL}$ polyethylene tube. Ceramic scissors were chosen to prevent any pollution from the use of stainless steel scissors (iron, chromium, or nickel). The duration of the $\mathrm{TNCl}$ protocol is less than $25 \mathrm{~min}$, compared to more than $1 \mathrm{~h}$ for the other two methods (WAWAW and TN).

To test the repeatability of the new washing protocol $(\mathrm{TNCl})$, the following experimentation was carried out. Sample 14 (blond female adult) was divided into five strands (A-E) of the same length and weight (between 4 and $5 \mathrm{~cm}$ and $\sim 250 \mathrm{mg}$ ). Strands A, B, and C were spiked, while strands $\mathrm{D}$ and $\mathrm{E}$ were not spiked. For the spiking test, each strand $(\mathrm{A}, \mathrm{B}$, and $\mathrm{C})$ was placed in a crystallizer for $6 \mathrm{~h}$ in contact with $30 \mathrm{~mL}$ UHQ water doped with a solution containing the 37 elements at concentrations between 10 and $80 \mathrm{mg} / \mathrm{L}$ depending on the element. The $\mathrm{pH}$ was between 5 and 6 . Then, the mixture (hair and doped solution) was kept at $50{ }^{\circ} \mathrm{C}$ until dry and rinsed with UHQ water in an ultrasonic bath for $5 \mathrm{~min}$. Strands D and E were used as control samples. D was in contact with only UHQ water without any elements, and $\mathrm{E}$ was not spiked or soaked in UHQ water. At the end, each strand (A, B, C, D, and E) was dried and divided into two, and each substrand (A1, A2, B1, B2, ...) was cut using ceramic scissors into segments of 2-5 $\mathrm{mm}$ and placed into a $50 \mathrm{~mL}$ polyethylene tube. The mineralization step was then carried out either directly for substrands A1, B1, ... or after washing for substrands $\mathrm{A} 2, \mathrm{~B} 2, \ldots$

\section{Mineralization}

For the mineralization step, $\sim 20 \mathrm{mg}$ of the hair sample was taken (from the $50 \mathrm{~mL}$ polyethylene tube if the sample was washed before), weighed using the precision balance, and placed in a $15 \mathrm{~mL}$ polypropylene tube with $0.5 \mathrm{~mL} 67 \%$ nitric acid solution. The tube, closed with screw caps, was placed in an ultrasound bath for $15 \mathrm{~min}$ and then in a graphite oven with the following thermal program: $10^{\circ} \mathrm{C} / \mathrm{min}$ up to $70^{\circ} \mathrm{C}$, maintain $70^{\circ} \mathrm{C}$ for $10 \mathrm{~min}, 10^{\circ} \mathrm{C} / \mathrm{min}$ up to $90^{\circ} \mathrm{C}$, and maintain this temperature for $6 \mathrm{~h}$. Then, the sample tube was filled at room temperature with $10 \mathrm{~mL}$ UHQ water and placed in the ultrasound bath for $15 \mathrm{~min}$. The sample solutions were then transferred into $15 \mathrm{~mL}$ polyethylene tubes that were closed until analysis.

\section{ICP-MS analysis}

The analysis of 37 elements was carried out using the ICPMS system, configured as follows: a sample feed rate of $0.3 \mathrm{~mL} / \mathrm{min}$, an RF power of $1550 \mathrm{~W}$, a chamber temperature of $2{ }^{\circ} \mathrm{C}$, and a plasma gas flow of $15 \mathrm{~L} / \mathrm{min}$. The elements were analyzed simultaneously with their isotopes (1-3) in "helium mode" if it was necessary to suppress polyatomic interferences by collision or "no gas" if no interferences were identified. The total acquisition time was 6 min with specific parameters used for each element (Table 1). A mix of six internal standards (Sc, Ge, Rh, Ir, In, 
Table 1 ICP-MS acquisition parameters for each element

\begin{tabular}{|c|c|c|c|c|}
\hline Element & Isotopes & Abundance $\%$ & $\begin{array}{l}\text { Istd } \\
\text { (amu) }\end{array}$ & Modes \\
\hline $\mathrm{Li}$ & $6 / 7$ & $92 / 8$ & $\mathrm{Sc}(45)$ & No gas \\
\hline $\mathrm{Be}$ & 9 & 100 & $\mathrm{Sc}(45)$ & No gas \\
\hline $\mathrm{Na}$ & 23 & 100 & $\mathrm{Sc}(45)$ & Helium \\
\hline $\mathrm{Mg}$ & $24 / 26$ & $79 / 10$ & $\mathrm{Sc}(45)$ & Helium \\
\hline $\mathrm{Al}$ & 27 & 100 & $\mathrm{Sc}(45)$ & $\begin{array}{l}\text { Helium and no } \\
\text { gas }\end{array}$ \\
\hline $\mathrm{P}$ & 31 & 100 & $\mathrm{Sc}(45)$ & $\begin{array}{l}\text { Helium and no } \\
\text { gas }\end{array}$ \\
\hline $\mathrm{K}$ & 39 & 93 & Sc (45) & Helium \\
\hline $\mathrm{Ca}$ & $43 / 44$ & $0.14 / 2.1$ & Ge (72) & No gas \\
\hline V & 51 & 99 & Ge (72) & Helium \\
\hline $\mathrm{Cr}$ & $52 / 53$ & $84 / 10$ & $\mathrm{Sc}(45)$ & Helium \\
\hline Mn & 55 & 100 & Sc (45) & Helium \\
\hline $\mathrm{Fe}$ & $56 / 54$ & $92 / 6$ & Sc (45) & Helium \\
\hline Co & 59 & 100 & $\mathrm{Sc}(45)$ & Helium \\
\hline $\mathrm{Ni}$ & $60 / 62$ & $26 / 3.6$ & $\mathrm{Sc}(45)$ & Helium \\
\hline $\mathrm{Cu}$ & $63 / 65$ & $69 / 31$ & Ge (72) & Helium \\
\hline $\mathrm{Zn}$ & $66 / 68$ & $28 / 19$ & Ge (72) & Helium \\
\hline As & 75 & 100 & Ge (72) & Helium \\
\hline $\mathrm{Se}$ & $78 / 82$ & $24 / 9$ & Ge (72) & $\begin{array}{l}\text { Hydrogen and no } \\
\text { gas }\end{array}$ \\
\hline $\mathrm{Sr}$ & $88 / 86$ & $83 / 10$ & $\mathrm{Rh}(103)$ & No gas \\
\hline Mo & $95 / 97$ & $16 / 10$ & Rh (103) & No gas \\
\hline $\mathrm{Ru}$ & $101 / 101 / 99$ & $17 / 13$ & Rh (103) & $\begin{array}{l}\text { Helium and no } \\
\text { gas }\end{array}$ \\
\hline $\mathrm{Ag}$ & 107/109 & $52 / 48$ & $\mathrm{Rh}(103)$ & No gas \\
\hline $\mathrm{Cd}$ & $114 / 111$ & $29 / 13$ & $\mathrm{Rh}(103)$ & No gas \\
\hline $\mathrm{Sn}$ & $120 / 118$ & $33 / 24$ & $\mathrm{Rh}(103)$ & $\begin{array}{l}\text { Helium and no } \\
\text { gas }\end{array}$ \\
\hline $\mathrm{Sb}$ & $121 / 123$ & $57 / 43$ & Rh (103) & No gas \\
\hline $\mathrm{Cs}$ & 133 & 100 & Ir (193) & $\begin{array}{l}\text { Helium and no } \\
\text { gas }\end{array}$ \\
\hline $\mathrm{Ba}$ & $137 / 135$ & $11 / 7$ & In (115) & No gas \\
\hline $\mathrm{La}$ & 139 & 99 & Ir (193) & $\begin{array}{l}\text { Helium and no } \\
\text { gas }\end{array}$ \\
\hline $\mathrm{Ce}$ & 140 & 88 & In (115) & No gas \\
\hline $\mathrm{Nd}$ & $146 / 143$ & $17 / 12$ & In (115) & No gas \\
\hline $\mathrm{Gd}$ & 157 & 16 & In (115) & No gas \\
\hline $\mathrm{Lu}$ & 175 & 97 & Ir (193) & $\begin{array}{l}\text { Helium and no } \\
\text { gas }\end{array}$ \\
\hline $\mathrm{Tl}$ & $205 / 203$ & $70 / 30$ & Ir (193) & No gas \\
\hline $\mathrm{Pb}$ & $\begin{array}{l}208 / 206 / \\
207\end{array}$ & $52 / 24 / 22$ & Ir (193) & No gas \\
\hline $\mathrm{Bi}$ & 209 & 100 & Ir (193) & No gas \\
\hline Th & 232 & 100 & $\operatorname{Re}(185)$ & $\begin{array}{l}\text { Helium and no } \\
\text { gas }\end{array}$ \\
\hline $\mathrm{U}$ & 238 & 99 & Ir (193) & No gas \\
\hline
\end{tabular}

and $\mathrm{Re}$ ) was added to each sample and the calibration point during nebulization to correct the matrix effect and normalize the signal. The calibration series was prepared using the same $67 \%$ nitric acid solution as the one used for the mineralization procedure. Some of the samples had to be diluted since they fell outside the calibration range. For each sample batch, two certified materials and two blanks (without the hair samples) were systematically analyzed.

The ICP-MS analysis was validated according to the protocol and the statistical tests described in the NF $\mathrm{T}$ 90-210 French standards [21]. Based on this reference, the calibration range for the 37 elements was obtained using seven concentration levels. The relative differences between the theoretical value and the measured value for each level were compared to the maximum acceptable deviation limit in the area studied. The instrumental limits of quantification (LOQs) were verified using accuracy tests at the limit of the quantification levels. The accuracy of the method was evaluated using ten series of reference material analyses, three concentration levels, and one to ten repetitions. The statistical tests enabled the calculation of the accuracy. Certified material control cards were created for each element to monitor any drift at the instrument or method level.

\section{Results and discussion}

Considering that washing is one pretreatment step of a whole analytical procedure (hair analysis) and that its evaluation depends on the analytical characteristics of the final method (mineralization and ICP-MS analysis), the performance evaluation of the washing procedure is presented after that of the analytical method.

\section{Performance of the analytical method}

Two reference materials were used (IAEA-086 and CRM$81002 \mathrm{~b}$ ), and the laboratory was involved in five interlaboratory tests (ILTs) to evaluate the method performance (mineralization and analysis steps). The results of the reference material analyses are presented in Table 2.

Among the 37 elements analyzed, 21 are covered by at least one of the reference materials (IAEA-086 or CRM$81002 \mathrm{~b}$ ), and seven are present in both reference materials ( $\mathrm{Ca}, \mathrm{Cu}, \mathrm{Mg}, \mathrm{Mn}, \mathrm{Fe}, \mathrm{Se}$, and $\mathrm{Zn}$ ). The list of elements present in the samples prepared for the ILTs was different in 22 elements (the ones in Table 2, except for $\mathrm{Na}, \mathrm{Mg}, \mathrm{K}, \mathrm{Ca}$, $\mathrm{Fe}, \mathrm{P}, \mathrm{Sr}, \mathrm{Be}, \mathrm{Bi}, \mathrm{Ni}, \mathrm{Sb}, \mathrm{Sn}, \mathrm{Th}, \mathrm{Tl}$, and U). Finally, eight elements ( $\mathrm{La}, \mathrm{Li}, \mathrm{Lu}, \mathrm{Ce}, \mathrm{Cs}, \mathrm{Gd}, \mathrm{Nd}$, and $\mathrm{Ru}$ ) were not included in the reference materials or ILTs.

With regard to the reference materials, the average concentration was calculated for each element, with the relative standard deviation (RSD) indicating the dispersion of the results and the repeatability of the method. The recovery rate was also calculated by dividing the measured values by 
Table 2 Results of reference material analyses

\begin{tabular}{|c|c|c|c|c|c|c|c|c|}
\hline \multirow[b]{3}{*}{ Elements } & \multicolumn{4}{|c|}{ Ref. material IAEA-086 } & \multicolumn{4}{|c|}{ Ref. material CRM-81002b } \\
\hline & \multicolumn{2}{|c|}{ Concentration $(\mu \mathrm{g} / \mathrm{g})$} & \multirow{2}{*}{$\begin{array}{l}\operatorname{RSD}(\%) \\
(n=51)\end{array}$} & \multirow[t]{2}{*}{ Recov. $(\%)$} & \multicolumn{2}{|c|}{ Concentration $(\mu \mathrm{g} / \mathrm{g})$} & \multirow{2}{*}{$\begin{array}{l}\text { RSD (\%) } \\
(n=45)\end{array}$} & \multirow[t]{2}{*}{ Recov. $(\%)$} \\
\hline & Reference & Measure & & & Reference & Measure & & \\
\hline $\mathrm{Na}$ & & 66 & 17 & & $445 \pm 40$ & 482 & 5 & 108 \\
\hline $\mathrm{Mg}$ & 176.5 & 153 & 8 & 87 & $248 \pm 14$ & 223 & 5 & 90 \\
\hline $\mathrm{Al}$ & & 40.7 & 12 & & $23.2 \pm 2.0$ & $16.0^{\mathrm{a}}$ & 27 & 69 \\
\hline $\mathrm{P}$ & & 111 & 11 & & $174 \pm 43$ & 135 & 6 & 78 \\
\hline $\mathrm{K}$ & & 38.18 & 9 & & 14.4 & $<50$ & N.C. & \\
\hline $\mathrm{Ca}$ & 1120 & 939 & 8 & 84 & $1537 \pm 68$ & 1424 & 6 & 93 \\
\hline V & & 0.32 & 8 & & 0.089 & 0.074 & 12 & \\
\hline $\mathrm{Cr}$ & & 2.42 & $13^{\mathrm{a}}$ & & $8.74 \pm 0.97$ & 6.20 & 9 & 83 \\
\hline $\mathrm{Fe}$ & $123 \pm 13$ & 89.0 & 9 & 72 & $160 \pm 16$ & 140 & 9 & 88 \\
\hline $\mathrm{Mn}$ & 9.6 & 8.55 & 8 & 89 & $3.83 \pm 0.39$ & 3.10 & 6 & 81 \\
\hline $\mathrm{Co}$ & & $<0.25$ & N.C. & & $0.153 \pm 0.015$ & $<0.25$ & N.C. & \\
\hline $\mathrm{Cu}$ & 17.55 & 15.8 & $9^{\mathrm{a}}$ & 90 & $33.6 \pm 2.3$ & 34.3 & 16 & 102 \\
\hline $\mathrm{Zn}$ & $166.5 \pm 7.5$ & 155 & 8 & 93 & $191 \pm 16$ & 192 & 5 & 101 \\
\hline As & & $<0.2$ & N.C. & & $0.198 \pm 0.023$ & 0.219 & 20 & 111 \\
\hline $\mathrm{Se}$ & 1.065 & 1.08 & 10 & 101 & $0.59 \pm 0.04$ & $<1$ & N.C. & \\
\hline $\mathrm{Sr}$ & & 7.13 & 7 & & $8.17 \pm 0.69$ & 7.02 & 6 & 86 \\
\hline Mo & & $<0.125$ & N.C & & $1.06 \pm 0.12$ & 0.656 & 9 & 62 \\
\hline $\mathrm{Ag}$ & & 1.52 & 15 & & $0.037 \pm 0.002$ & $<0.1$ & N.C & \\
\hline $\mathrm{Cd}$ & & 0.142 & 10 & & $0.072 \pm 0.010$ & 0.060 & 10 & 83 \\
\hline $\mathrm{Ba}$ & & 5.02 & 8 & & $11.1 \pm 1.3$ & 10.3 & $31^{\mathrm{b}}$ & 93 \\
\hline $\mathrm{Pb}$ & & 9.59 & 8 & & $3.83 \pm 0.18$ & 3.94 & 11 & 103 \\
\hline
\end{tabular}

N.C. not calculated

${ }^{a}$ RSD estimated with $n=50$

${ }^{\mathrm{b}} \mathrm{RSD}$ estimated with $n=44$

the certified ones (reference). The comparison between the results in Table 2 shows that the majority of the measured values were statistically comparable with the certified values. Some elements were outside the confidence interval (for example, $\mathrm{Ca}, \mathrm{Mg}$, and $\mathrm{Fe}$ ), but the recoveries fitted the laboratory criteria of 70-110\%, except for $\mathrm{Al}(69 \%)$ and Mo (62\%). Concerning the RSD, only two elements had RSDs above the laboratory criteria of $20 \%$ but lower than $35 \%$, i.e., $\mathrm{Al}(27 \%)$ and $\mathrm{Ba}(31 \%)$ in CRM-81002b.

To complete the comparison with the certified materials, five ILTs were carried out under the supervision of INSPQ (Institut National de Santé Publique du Québec, Canada). The results were expressed for each element by the z-score calculation, determined by the difference between the laboratory value and the designated value (according to ISO 13528: 2005). For the ILTs of our laboratory and the 23 elements, all z-score values were lower than 2 , meaning that the results were comparable to those obtained by other laboratories. The average recovery rate calculated by dividing the average of the measured values by the designated values had values between 70 and $110 \%$ for all elements except for $\mathrm{Se}(118 \%)$ and $\mathrm{Sn}(67 \%)$. The z-score values and the average recovery rate were determined according to the number of participants in each trial (between 14 and 32).

\section{Washing protocol performance evaluation}

\section{Washing efficiency: comparison of methods}

Washing efficiency is defined as the percentage of the elemental concentration in hair removed by washing. It is calculated from the ratio of the difference between the measured concentrations before and after washing to the concentration in the raw sample (unwashed). The washing method efficiency was evaluated for 23 elements and the three different protocols (WAWAW, TN, and $\mathrm{TNCl}$ ) applied to samples 11,12, and 13, which were treated and analyzed three times. As shown in Table 3, the washing efficiency was below $20 \%$ for the WAWAW protocol, with the exception of $\mathrm{Cr}(39 \%)$ and $\mathrm{Sb}(23 \%)$. The average of the washing efficiency values for all elements with a 
Table 3 The fraction of each element in hair removed by washing for the three washing methods performed on samples 11, 12, and 13 $(n=3)$

\begin{tabular}{|c|c|c|c|c|}
\hline \multirow[t]{2}{*}{ Element } & \multirow{2}{*}{$\begin{array}{l}\mathrm{C}^{\mathrm{a}}(\mu \mathrm{g} / \mathrm{g}) \\
\text { Unwashed }\end{array}$} & \multicolumn{3}{|c|}{ Washing efficiency $(\%)(n=3)$} \\
\hline & & WAWAW & $\mathrm{TN}$ & $\mathrm{TNCl}$ \\
\hline $\mathrm{Na}$ & 169 & -22 & 96 & 97 \\
\hline $\mathrm{Mg}$ & 283 & -1 & 71 & 80 \\
\hline $\mathrm{Al}$ & 14 & 10 & 51 & 63 \\
\hline $\mathrm{P}$ & 231 & 13 & 8 & 6 \\
\hline $\mathrm{K}$ & 60 & -40 & 87 & 89 \\
\hline $\mathrm{Ca}$ & 5924 & 16 & 83 & 89 \\
\hline $\mathrm{V}$ & 0.09 & 6 & 25 & 15 \\
\hline $\mathrm{Cr}$ & 1.1 & 39 & 13 & 3 \\
\hline $\mathrm{Fe}$ & 25.3 & 17 & -18 & 20 \\
\hline $\mathrm{Mn}$ & 1.7 & 7 & 45 & 76 \\
\hline Co & 0.78 & 6 & 25 & 26 \\
\hline $\mathrm{Ni}$ & 2 & -9 & 44 & 71 \\
\hline $\mathrm{Cu}$ & 32 & 5 & 46 & 46 \\
\hline $\mathrm{Zn}$ & 286 & 2 & 60 & 74 \\
\hline $\mathrm{Sr}$ & 11.30 & 7 & 78 & 85 \\
\hline $\mathrm{Ag}$ & 0.72 & 0 & -22 & 25 \\
\hline $\mathrm{Cd}$ & 0.07 & 6 & 71 & 79 \\
\hline $\mathrm{Sn}$ & 1.3 & 7 & 28 & 26 \\
\hline $\mathrm{Sb}$ & 0.1 & 23 & 10 & -1 \\
\hline $\mathrm{Ba}$ & 5.4 & 3 & 70 & 77 \\
\hline $\mathrm{Pb}$ & 2.1 & -1 & 78 & 88 \\
\hline $\mathrm{Bi}$ & 0.29 & -14 & 44 & 66 \\
\hline $\mathrm{U}$ & 0.030 & 0 & 56 & 65 \\
\hline Mean & 4 & 45 & 54 & \\
\hline
\end{tabular}

${ }^{\text {aAverage concentration }(n=3)}$

concentration superior to the LOQ was $4 \%$, indicating no significant change in their concentrations after washing. The TN washing protocol led to a mean washing efficiency of $45 \%$, with some elements not extracted ( $\mathrm{Fe}$ and $\mathrm{Ag}$ ). For the $\mathrm{TNCl}$ method, the addition of hydrochloric acid at the third stage provided better results, with an average washing efficiency of 54\% for all elements. The comparison between the $\mathrm{TN}$ and $\mathrm{TNCl}$ protocols shows a better extraction for $\mathrm{TNCl}$ for all elements except for $\mathrm{Na}, \mathrm{K}, \mathrm{Ca}, \mathrm{Co}, \mathrm{Cu}$, and $\mathrm{Sn}$ (similar results) and $\mathrm{V}, \mathrm{Cr}$, and $\mathrm{Sb}$ (lower). However, contrary to the other two protocols including steps of acidic extraction, the WAWAW protocol seems to eliminate very few elements (in our samples) and probably cleans only a part of the particulates deposited on the surface of the hair. The eight elements less impacted by all washing methods were $\mathrm{P}, \mathrm{V}, \mathrm{Cr}, \mathrm{Fe}, \mathrm{Ag}, \mathrm{Sn}, \mathrm{Sb}$, and $\mathrm{Co}$, with a washing efficiency of less than $30 \%$. The $\mathrm{TNCl}$ protocol was thus chosen for its ability to extract the elements more strongly bonded with the structure of the hair.

\section{Spiked and nonspiked samples}

The interest of working on spiked and nonspiked samples was to test the repeatability of spiking and washing steps. A further benefit of spiking was also to test all 37 elements, with some of them being not detected in nonspiked hair samples. Washing tests were applied to sample 14 . The results of the three strands A, B, and C with the spiking protocol applied and the results of samples D and E processed without spiking (see section 2.4.1) are shown in Table 4. The results show that the concentrations of inorganics after washing are higher for the spiked samples than for the nonspiked ones, except for $\mathrm{Ca}$ and, to a lesser degree, for $\mathrm{Mg}, \mathrm{Zn}, \mathrm{Sr}$, and $\mathrm{Sn}$. This could be explained by the use of acidic doping solutions for these elements in the spiking protocol, which could improve the washing rate for the spiked samples, and by the high values of RSD for $\mathrm{Ca}, \mathrm{Sr}$, and $\mathrm{Pb}$. For the spiked and unwashed $\mathrm{A}, \mathrm{B}$, and $\mathrm{C}$ samples, all elements were recovered with an RSD lower than $20 \%$, reflecting the homogeneity of strand sampling on hair as well as the repeatability of all steps (spiking, mineralization and analysis). For the spiked and washed $\mathrm{A}, \mathrm{B}$, and $\mathrm{C}$ samples, $\sim 25 \%$ of the elements were not detected (measurements below the LOQ) and the RSD increased by almost $50 \%$ due to the low values measured after washing and the existence of a supplementary step (washing) in the whole procedure. For the nonspiked and unwashed D and E samples, only 15 elements of the 37 were detected, with very low RSDs except for Sn (44\%). Finally, for the nonspiked and washed D and E samples, only 10 elements were detected with an RSD lower than $20 \%$, except for $\mathrm{Pb}(37 \%)$. These results also show that the step of soaking in water for sample D has no impact on the results.

Considering the behavior of the elements during the washing step, the majority of the elements can be considered as washable $(86 \%$ of the elements have a washing efficiency $>60 \%$ ) for the spiked samples (A, B, and $\mathrm{C})$, except for $\mathrm{Se}, \mathrm{Mo}, \mathrm{Ag}, \mathrm{Bi}$, and Th. For the nonspiked samples (D and E), 67\% of the detected elements were washable, except for $\mathrm{P}, \mathrm{Fe}, \mathrm{Zn}, \mathrm{Ag}$, and $\mathrm{Sn}$. The elements less washable were $\mathrm{Se}, \mathrm{P}$, and $\mathrm{Sn}$. The comparison of the two lists of the elements that were less washable for the spiked and nonspiked samples must consider that the spiking step does not guarantee that the spiked elements are as strongly bonded with the hair matrix as in the raw samples (nonspiked). The number of elements easily washable (>90\%) drops from 24 for the spiked samples to 5 for the nonspiked ones ( $\mathrm{Al}, \mathrm{Mn}, \mathrm{Co}, \mathrm{Pb}$, and $\mathrm{Bi}$ ). This result was obtained for only one hair strand (sample 14) and should be confirmed for the other samples. 
Table 4 Comparisons between the spiked/nonspiked samples with/without washing: concentration, RSD, and fraction of each element removed by washing $(\%)$

\begin{tabular}{|c|c|c|c|c|c|c|c|c|c|c|c|}
\hline \multirow[t]{3}{*}{ Elements } & \multirow[t]{3}{*}{ LOQ $(\mu \mathrm{g} / \mathrm{g})$} & \multicolumn{5}{|c|}{ A. B. C spiked samples } & \multicolumn{5}{|c|}{ D and E non-spiked samples } \\
\hline & & \multicolumn{2}{|c|}{ Unwashed $(n=9)$} & \multicolumn{2}{|c|}{ Washed $(n=9)$} & \multirow[t]{2}{*}{$\%$ washed } & \multicolumn{2}{|c|}{ Unwashed $(n=6)$} & \multicolumn{2}{|c|}{ Washed $(n=6)$} & \multirow[t]{2}{*}{$\%$ washed } \\
\hline & & Conc. & $\operatorname{RSD}(\%)$ & Conc. & $\operatorname{RSD}(\%)$ & & Conc. & $\operatorname{RSD}(\%)$ & Conc. & $\operatorname{RSD}(\%)$ & \\
\hline $\mathrm{Li}$ & 3 & 220 & $15 \%$ & $<\mathrm{LOQ}$ & N.C. & $100 \%$ & $<\mathrm{LOQ}$ & N.C. & $<$ LOQ & N.C. & N.C. \\
\hline $\mathrm{Be}$ & 0.05 & 2.46 & $13 \%$ & 0.09 & $47 \%$ & $96 \%$ & $<\mathrm{LOQ}$ & N.C. & $<$ LOQ & N.C. & N.C. \\
\hline $\mathrm{Na}$ & 50 & 1299 & $14 \%$ & $<\mathrm{LOQ}$ & N.C. & $100 \%$ & $<\mathrm{LOQ}$ & N.C. & $<$ LOQ & N.C. & N.C. \\
\hline $\mathrm{Mg}$ & 25 & 1183 & $13 \%$ & 33 & $5 \%$ & $97 \%$ & 128 & $11 \%$ & 47 & $17 \%$ & $63 \%$ \\
\hline $\mathrm{Al}$ & 10 & 120 & $15 \%$ & $<\mathrm{LOQ}$ & N.C. & $100 \%$ & 20 & $11 \%$ & $<\mathrm{LOQ}$ & N.C. & $100 \%$ \\
\hline $\mathrm{P}$ & 25 & 678 & $14 \%$ & 96 & $6 \%$ & $86 \%$ & 98 & $3 \%$ & 89 & $9 \%$ & $9 \%$ \\
\hline $\mathrm{K}$ & 50 & 1119 & $15 \%$ & $<\mathrm{LOQ}$ & N.C. & $100 \%$ & $<\mathrm{LOQ}$ & N.C. & $<\mathrm{LOQ}$ & N.C. & N.C. \\
\hline $\mathrm{Ca}$ & 100 & 6972 & $12 \%$ & 252 & $38 \%$ & $96 \%$ & 3500 & $6 \%$ & 787 & $10 \%$ & $77 \%$ \\
\hline V & 0.05 & 1.18 & $14 \%$ & 0.12 & $30 \%$ & $90 \%$ & $<\mathrm{LOQ}$ & N.C. & $<\mathrm{LOQ}$ & N.C. & N.C. \\
\hline $\mathrm{Cr}$ & 0.5 & 10.9 & $13 \%$ & 1.0 & $33 \%$ & $91 \%$ & $<\mathrm{LOQ}$ & N.C. & $<\mathrm{LOQ}$ & N.C. & N.C. \\
\hline $\mathrm{Fe}$ & 2.5 & 125 & $13 \%$ & 20.7 & $31 \%$ & $83 \%$ & 17.7 & $8 \%$ & 9.5 & $17 \%$ & $46 \%$ \\
\hline $\mathrm{Mn}$ & 0.5 & 11.9 & $15 \%$ & $<\mathrm{LOQ}$ & N.C. & $100 \%$ & 0.5 & $5 \%$ & $<\mathrm{LOQ}$ & N.C. & $100 \%$ \\
\hline Co & 0.25 & 1.49 & $13 \%$ & 0.19 & $12 \%$ & $87 \%$ & 0.38 & $9 \%$ & $<\mathrm{LOQ}$ & N.C. & $100 \%$ \\
\hline $\mathrm{Ni}$ & 2 & 12 & $13 \%$ & $<\mathrm{LOQ}$ & N.C. & $100 \%$ & $<\mathrm{LOQ}$ & N.C. & $<\mathrm{LOQ}$ & N.C. & N.C. \\
\hline $\mathrm{Cu}$ & 1 & 62 & $12 \%$ & 12 & $18 \%$ & $81 \%$ & 20 & $16 \%$ & 6.9 & $7 \%$ & $65 \%$ \\
\hline $\mathrm{Zn}$ & 5 & 201 & $13 \%$ & 20 & $19 \%$ & $90 \%$ & 130 & $7 \%$ & 66 & $7 \%$ & $49 \%$ \\
\hline As & 0.2 & 2.9 & $16 \%$ & 0.3 & $49 \%$ & $91 \%$ & $<\mathrm{LOQ}$ & N.C. & $<\mathrm{LOQ}$ & N.C. & N.C. \\
\hline $\mathrm{Se}$ & 1 & 31 & $7 \%$ & 35 & $8 \%$ & $-11 \%$ & $<\mathrm{LOQ}$ & N.C. & $<\mathrm{LOQ}$ & N.C. & N.C. \\
\hline $\mathrm{Sr}$ & 0.25 & 13.7 & $12 \%$ & 0.47 & $37 \%$ & $97 \%$ & 3.61 & $10 \%$ & 1.0 & $16 \%$ & $71 \%$ \\
\hline Mo & 0.125 & 3.35 & $8 \%$ & 1.39 & $15 \%$ & $59 \%$ & $<\mathrm{LOQ}$ & N.C. & $<\mathrm{LOQ}$ & N.C. & N.C. \\
\hline $\mathrm{Ru}$ & 0.05 & 2.46 & $12 \%$ & 0.87 & $20 \%$ & $65 \%$ & $<\mathrm{LOQ}$ & N.C. & $<\mathrm{LOQ}$ & N.C. & N.C. \\
\hline $\mathrm{Ag}$ & 0.05 & 1.53 & $6 \%$ & 0.79 & $16 \%$ & $48 \%$ & 0.85 & $13 \%$ & 0.36 & $17 \%$ & $58 \%$ \\
\hline $\mathrm{Cd}$ & 0.05 & 0.61 & $14 \%$ & $<\mathrm{LOQ}$ & N.C. & $100 \%$ & $<\mathrm{LOQ}$ & N.C. & $<\mathrm{LOQ}$ & N.C. & N.C. \\
\hline Sn & 0.1 & 2.6 & $3 \%$ & 0.7 & $10 \%$ & $73 \%$ & 0.8 & $44 \%$ & 0.9 & $18 \%$ & $0 \%$ \\
\hline $\mathrm{Sb}$ & 0.2 & 2.1 & $8 \%$ & 0.6 & $18 \%$ & $71 \%$ & $<\mathrm{LOQ}$ & N.C. & $<\mathrm{LOQ}$ & N.C. & N.C. \\
\hline Cs & 0.05 & 2.33 & $14 \%$ & $<\mathrm{LOQ}$ & N.C. & $100 \%$ & $<\mathrm{LOQ}$ & N.C. & $<\mathrm{LOQ}$ & N.C. & N.C. \\
\hline $\mathrm{Ba}$ & 0.5 & 26.1 & $13 \%$ & 1.0 & $36 \%$ & $96 \%$ & 2.9 & $7 \%$ & 0.8 & $16 \%$ & $72 \%$ \\
\hline $\mathrm{La}$ & 0.1 & 2.4 & $15 \%$ & 0.2 & $35 \%$ & $93 \%$ & $<\mathrm{LOQ}$ & N.C. & $<\mathrm{LOQ}$ & N.C. & N.C. \\
\hline $\mathrm{Ce}$ & 0.125 & 6.07 & $15 \%$ & 0.471 & $35 \%$ & $92 \%$ & $<\mathrm{LOQ}$ & N.C. & $<\mathrm{LOQ}$ & N.C. & N.C. \\
\hline $\mathrm{Nd}$ & 0.025 & 0.63 & $15 \%$ & 0.048 & $34 \%$ & $92 \%$ & $<\mathrm{LOQ}$ & N.C. & $<\mathrm{LOQ}$ & N.C. & N.C. \\
\hline $\mathrm{Gd}$ & 0.025 & 1.21 & $14 \%$ & 0.073 & $34 \%$ & $94 \%$ & $<\mathrm{LOQ}$ & N.C. & $<\mathrm{LOQ}$ & N.C. & N.C. \\
\hline $\mathrm{Lu}$ & 0.05 & 2.38 & $14 \%$ & 0.14 & $34 \%$ & $94 \%$ & $<\mathrm{LOQ}$ & N.C. & $<\mathrm{LOQ}$ & N.C. & N.C. \\
\hline $\mathrm{Tl}$ & 0.05 & 2.83 & $15 \%$ & $<\mathrm{LOQ}$ & N.C. & $100 \%$ & $<\mathrm{LOQ}$ & N.C. & $<\mathrm{LOQ}$ & N.C. & N.C. \\
\hline $\mathrm{Pb}$ & 0.1 & 5.1 & $12 \%$ & 0.4 & $46 \%$ & $92 \%$ & 0.48 & $14 \%$ & 0.13 & $37 \%$ & $73 \%$ \\
\hline $\mathrm{Bi}$ & 0.05 & 1.50 & N.C. & 0.75 & N.C. & $50 \%$ & 0.10 & N.C. & $<\mathrm{LOQ}$ & N.C. & $100 \%$ \\
\hline Th & 0.1 & 2.47 & $2 \%$ & 1.1 & $15 \%$ & $56 \%$ & $<\mathrm{LOQ}$ & N.C. & $<\mathrm{LOQ}$ & N.C. & N.C. \\
\hline $\mathrm{U}$ & 0.025 & 1.55 & $17 \%$ & 0.373 & $26 \%$ & $76 \%$ & $<\mathrm{LOQ}$ & N.C. & $<\mathrm{LOQ}$ & N.C. & N.C. \\
\hline
\end{tabular}

$L O Q$ limit of quantification, N.C. not calculable, Conc. concentration

\section{Test on real hair samples}

The analytical method (mineralization and analysis) was applied on 10 samples (1-10) without and with the washing step. Of the 37 elements analyzed, 24 were detected (concentration higher than the LOQ) in at least one sample. The results are shown in Figure 2 in a box-plot format, with the elements presented in three groups. For the box-plot representation, only 22 elements were considered (at least two values higher than the LOQ).

The average concentration of the first group ( $\mathrm{Na}, \mathrm{Mg}, \mathrm{K}$, $\mathrm{Ca}$, and $\mathrm{P}$ ) ranged from 1746 to $47 \mu \mathrm{g} . \mathrm{g}-1$ for the raw 

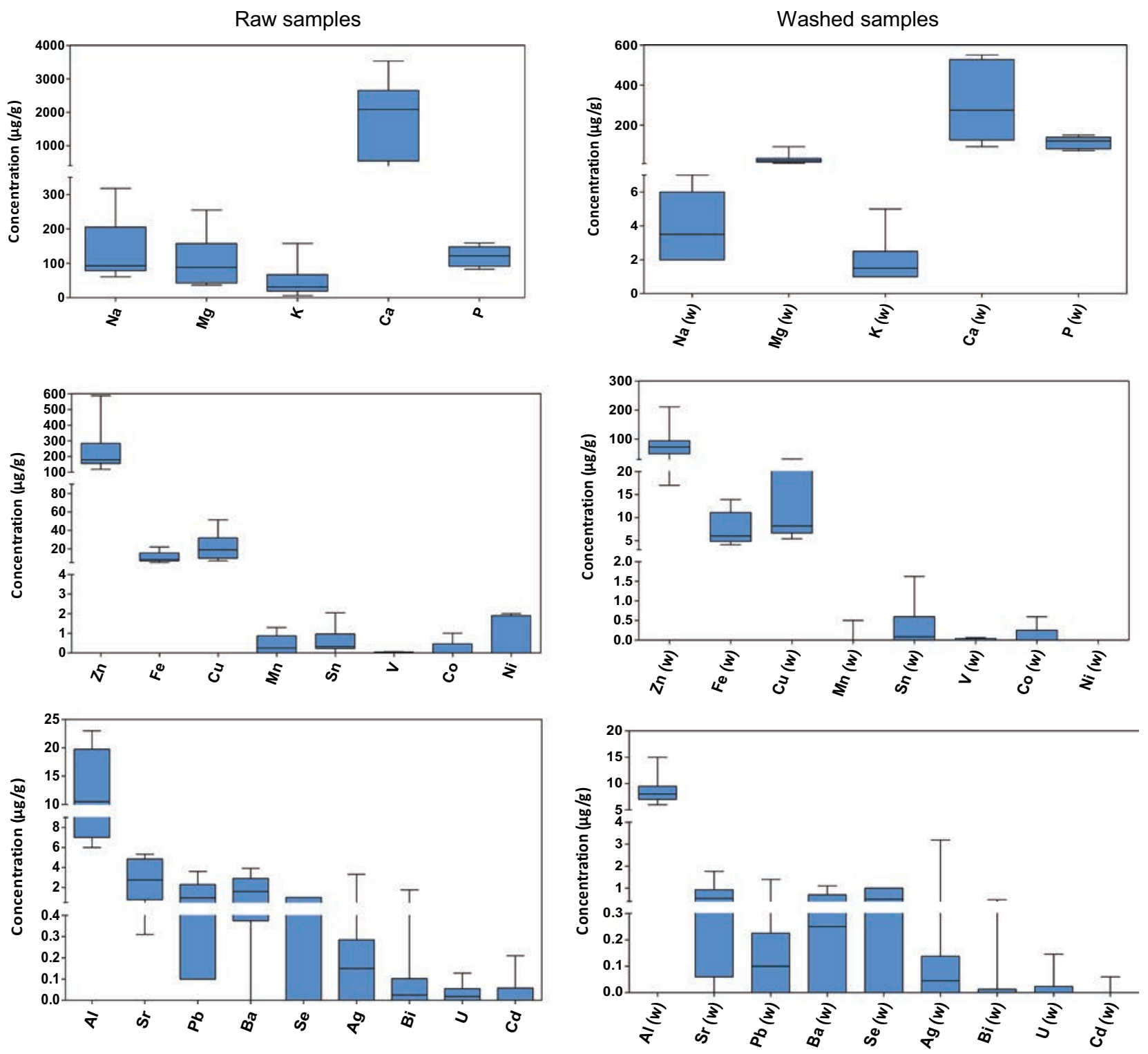

Fig. 2 Concentration levels (box-plots) of some elements in the hair samples (raw samples and washed samples)

samples and from 307 to $2 \mu \mathrm{g} . \mathrm{g}-1$ after washing, corresponding to $\mathrm{Ca}$ and $\mathrm{K}$. The average concentration of the second group ( $\mathrm{Zn}, \mathrm{Fe}, \mathrm{Cu}, \mathrm{Mn}, \mathrm{Sn}, \mathrm{V}, \mathrm{Co}$, and $\mathrm{Ni}$ ) ranged from 238 to $0.02 \mu \mathrm{g} . \mathrm{g}-1$ for the raw samples and from 80 to $0.015 \mu \mathrm{g} . \mathrm{g}-1$ after washing, corresponding to $\mathrm{Zn}$ and $\mathrm{V}$. The average concentration of the last group of elements $(\mathrm{Pb}$, $\mathrm{Al}, \mathrm{Ag}, \mathrm{Sr}, \mathrm{Ba}, \mathrm{Cr}, \mathrm{Sb}, \mathrm{Cd}, \mathrm{Bi}, \mathrm{Se}$, and $\mathrm{U}$ ) ranged from 12.8 to $0.027 \mu \mathrm{g} . \mathrm{g}^{-1}$ for the raw samples and from 8.6 to $0.02 \mu \mathrm{g}$. $\mathrm{g}^{-1}$ after washing, corresponding to $\mathrm{Al}$ and $\mathrm{Sb}$.

The washing efficiency ranged from 97 to $6 \%$ for $\mathrm{Na}$ and $\mathrm{P}, 88$ to $28 \%$ for $\mathrm{Mn}$ and $\mathrm{Fe}$, and 83 to $15 \%$ for $\mathrm{Cd}$ and $\mathrm{Cr}$. These values are comparable with those in Table 3 for $75 \%$ of the detected elements. Only six elements with a concentration close to the LOQ had a washing efficiency different from that in Table 3 (Al, Ag, Sn, V, Cr, and $\mathrm{Sb}$ ).

\section{Discussion}

The first comparison is made between the performances of different washing methods found in the literature over the past 40 years (Table 5). Anionic (sodium lauryl sulfate, SLS) or non-ionic surfactants (Triton X-100) have mainly been used, followed by organic solvents (acetone or isopropanol) and acid solutions (nitric or hydrochloric), alone or in multistage methods (WAWAW, TN, and TNCl). Regarding the washing efficiency, the general trend is that the methods including an acidic stage show higher values 
Table 5 The fraction of each element removed by different washing methods: some literature data

\begin{tabular}{|c|c|c|c|c|c|c|c|c|c|c|c|}
\hline References & $\mathrm{Mg}$ & $\mathrm{K}$ & $\mathrm{Ca}$ & $\mathrm{Zn}$ & $\mathrm{Fe}$ & $\mathrm{Cu}$ & $\mathrm{Mn}$ & $\mathrm{Pb}$ & $\mathrm{Cd}$ & $\mathrm{Cr}$ & $\mathrm{Se}$ \\
\hline \multicolumn{12}{|l|}{ [38] } \\
\hline SLS & 60 & n.a. & n. $a$ & 9 & n.a & 24 & n.a & n. $a$ & n.a & n. $a$ & n.a \\
\hline \multicolumn{12}{|l|}{ [39] } \\
\hline acetone & n. $a$ & n. $a$ & n. $a$ & 38.6 & 48.5 & 19.8 & 29.6 & n. $a$ & 26.3 & n. $a$ & n.a \\
\hline \multicolumn{12}{|l|}{ [24] } \\
\hline Triton & 17.8 & 70.1 & 0.7 & 0.5 & n.a & 9.1 & n. $a$ & 17.4 & 19.6 & 32.1 & -1 \\
\hline SLS & 11.9 & 81.2 & 23.7 & 7.3 & n.a & 12.2 & n.a & 17.4 & 3.2 & 45.2 & 8.9 \\
\hline EDTA & 20.6 & 92.3 & 26.9 & 11 & n.a & 20.8 & n. $a$ & 29.8 & -6 & 37.5 & -24 \\
\hline acetone & 11.5 & 82.7 & 18.2 & 2.4 & n.a & 11.2 & n. $a$ & 20.2 & 40.2 & 40.7 & 13.2 \\
\hline \multicolumn{12}{|l|}{ [40] } \\
\hline $\mathrm{H}_{2} \mathrm{O}$ & n.a & n.a & n.a & n.a & n.a & n.a & n.a & 10 & 15 & 9.6 & -23.9 \\
\hline isoprop & n.a & n.a & n.a & n.a & n.a & n.a & n.a & 24 & 15 & 9.6 & -32.7 \\
\hline $\mathrm{HCl}$ & n.a & n.a & n.a & n.a & n.a & n.a & n.a & 61 & 59 & 8.2 & -50.2 \\
\hline SLS & n. $a$ & n. $a$ & n.a & n.a & n.a & n.a & n. $a$ & 25 & 15 & 16.4 & -1.4 \\
\hline shampoo & n.a & n. $a$ & n.a & n.a & n.a & n.a & n.a & 33 & 68 & 17.7 & -11.6 \\
\hline \multicolumn{12}{|l|}{ [20] } \\
\hline $\mathrm{H}_{2} \mathrm{O}$ & n.a & n.a & n.a & n.a & n.a & 7.0 & 22.7 & -2.1 & n.a & 11.7 & n. $a$ \\
\hline Triton & n.a & n.a & n.a & n.a & n.a & 38.6 & 49.7 & 12.6 & n.a & 28.9 & n. $a$ \\
\hline $\mathrm{TN}$ & n.a & n.a & n.a & n.a & n.a & 66.7 & 79.6 & 68.6 & n.a & 33.7 & n.a. \\
\hline $3 \mathrm{TN}$ & n.a & n.a & n.a & n.a & n.a & 76.1 & 92.1 & 89.4 & n.a & 50.9 & n.a \\
\hline \multicolumn{12}{|l|}{ this study } \\
\hline $\mathrm{TNCl}$ & 70.8 & 95.7 & 82.4 & 66.1 & 28.5 & 35.1 & 88.1 & 81.9 & 83.3 & 15.1 & - \\
\hline $\mathrm{TNCl}^{\mathrm{a}}$ & 63 & 100 & 77 & 49 & 46 & 65 & 100 & 100 & 100 & 91 & -11 \\
\hline
\end{tabular}

$S L S$ sodium lauryl sulfate, isoprop isopropanol, $3 T N$ TN method is repeated three times

${ }^{a}$ Results of washing test for $\mathrm{Mg}, \mathrm{Ca}, \mathrm{Zn}, \mathrm{Cu}, \mathrm{Mn}, \mathrm{Pb}$, and $\mathrm{Cd}$. The choice of washing reagents and the efficiency of inorganic acids such as nitric or hydrochloric acids, at a very low $\mathrm{pH}$, are coherent with the observations reported by Akcil [22] for the washing of metals in contaminated sediments. In particular, the oxidizing properties of nitric acid could destroy organometallic complexes more effectively, but hydrochloric acid is suitable for extracting heavy metals from dredged marine sediments [23]. An acidic $\mathrm{pH}$, obtained through the washing step, is required for the element extraction, and hydrochloric acid shows a similar or lower heavy-metal removal efficiency compared to nitric acid [22]; however, their sequential use provides the same results as the three time TN protocol (Table 5).

For the other elements, $\mathrm{K}$ is easily washable with any method; $\mathrm{Fe}$ is extracted at $\sim 30-50 \%$ with both acetone and $\mathrm{TNCl}$, and $\mathrm{Cr}$ shows different values of washing efficiency depending on the study. Finally, Se has a very different behavior, with a majority of negative values, except for one experiment (washing with acetone, [24]).

For the extraction of $\mathrm{Se}$, the presence of an organic matrix prevents its recovery, and a specific method should be carried out for the extraction from soils rich inorganic matter [25]. The existence of strong bonding in the hair matrix, the low concentrations of Se in the samples, and the presence of traces in the reagents could explain the negative values in Table 5.

Another comparison can be made between the results for the hair concentrations of inorganics published recently (Table 6). A very recent study [13] was not retained, because the hair samples were collected from salons and barber shops and thus suspected to be more contaminated. Among the four papers selected for the analytical method (ICP-MS or OES) and the number of elements studied (five or more), the number of samples (children and adults) varied from 37 to close to 6000 , taken from healthy volunteers. The washing method was derived from the WAWAW protocol and identical for the four studies. This point and the number of samples are the main differences with the study reported in this paper. One of the studies [26] was a meta-analysis of almost 50 papers, among which only four were selected based on comparable characteristics. This review reported the ranges of concentrations for 16 elements. The results of the three monographs [15, 27, 28] are coherent with the review, except for $\mathrm{Al}$ and $\mathrm{Sr}$, which had much higher concentrations in the study by Raposo [27] (205 and $118 \mu \mathrm{g} . \mathrm{g}^{-1}$, respectively). Regarding our results, all values are within the range provided by the review of 
Table 6 Comparison of some hair concentrations of inorganics $\left(\mu \mathrm{g} \cdot \mathrm{g}^{-1}\right)$ in recent work

\begin{tabular}{|c|c|c|c|c|c|}
\hline Ref. & [15] & [27] & [28] & [26] & $\begin{array}{l}\text { this } \\
\text { study }\end{array}$ \\
\hline Year & 2016 & 2014 & 2015 & 2013 & \\
\hline Location & $\begin{array}{l}\text { Madrid } \\
(\mathrm{S})\end{array}$ & $\begin{array}{l}\text { Biscay } \\
\text { (S) }\end{array}$ & $\begin{array}{l}\text { Moscow } \\
(\mathrm{Ru})\end{array}$ & $\begin{array}{l}\text { Review } \\
\text { (four } \\
\text { studies) }\end{array}$ & $\begin{array}{l}\text { Rennes } \\
\text { (F) }\end{array}$ \\
\hline Number & $\begin{array}{l}648 \\
\text { Children }\end{array}$ & $\begin{array}{l}37-114 \\
\text { Child. } \\
\text { Adults }\end{array}$ & $\begin{array}{l}5908 \\
\text { Children }\end{array}$ & $\begin{array}{l}\text { 50-655 } \\
\text { Children }\end{array}$ & $\begin{array}{l}10 \\
\text { Child. } \\
\text { Adults }\end{array}$ \\
\hline $\begin{array}{l}\text { Washing } \\
\text { analysis }\end{array}$ & $\begin{array}{l}\text { Water- } \\
\text { acetone } \\
\text { ICP-MS }\end{array}$ & $\begin{array}{l}\text { Water- } \\
\text { acetone } \\
\text { ICP-MS }\end{array}$ & $\begin{array}{l}\text { Water- } \\
\text { acetone } \\
\text { ICP-OES }\end{array}$ & $\begin{array}{l}\text { Water- } \\
\text { acetone } \\
\text { ICP-MS }\end{array}$ & $\begin{array}{l}\text { Adults } \\
\text { TNCl } \\
\text { ICP-MS }\end{array}$ \\
\hline \multicolumn{6}{|l|}{ Element } \\
\hline $\mathrm{Al}$ & 23.8 & 205 & 5.7 & $0.01-16$ & 7.72 \\
\hline $\mathrm{Ag}$ & 0.421 & & & & 0.37 \\
\hline $\mathrm{Ba}$ & 0.8 & & & $0.10-2.70$ & 0.38 \\
\hline $\mathrm{Bi}$ & 0.07 & & 0.036 & $0-0.10$ & 0.052 \\
\hline $\mathrm{Ca}$ & & 638 & & $120-1460$ & 307.2 \\
\hline $\mathrm{Cd}$ & 0.029 & 0.072 & 0.015 & $0.003-0.2$ & 0.006 \\
\hline Co & 0.025 & & & $0.01-1.2$ & 0.114 \\
\hline $\mathrm{Cr}$ & 0.5 & & & $0.001-0.9$ & 0.033 \\
\hline $\mathrm{Cu}$ & 25.9 & 13.9 & & $8-59.7$ & 22.45 \\
\hline $\mathrm{Fe}$ & 17.3 & 17.4 & & $3.66-21$ & 7.72 \\
\hline $\mathrm{Mg}$ & & 16.5 & & $6.0-65.3$ & 29.9 \\
\hline $\mathrm{Mn}$ & 0.398 & & & $0.03-0.91$ & 0.05 \\
\hline $\mathrm{Na}$ & & 110 & & $2.0-123$ & 3.9 \\
\hline $\mathrm{P}$ & & & & $108-173$ & 114.4 \\
\hline $\mathrm{Pb}$ & 1.23 & 0.54 & 0.501 & $0.008-3.03$ & 0.23 \\
\hline $\mathrm{Se}$ & 1.0 & & & $0.03-1.28$ & 0.5 \\
\hline $\mathrm{Sr}$ & 2.23 & 118 & 1.119 & & 0.607 \\
\hline $\mathrm{Zn}$ & 131 & 261 & & $30-329$ & 80.5 \\
\hline
\end{tabular}

Mikulewicz [26] or close to the results of other studies for $\mathrm{Ag}$ and Sr. However, considering that the washing efficiency used for our study ( $\mathrm{TNCl})$ is better than that of the WAWAW (or derived) method due to the acidic stages in the protocol, the results are generally close to the lowest values of the ranges in the review. However, in any case, the variations in concentrations of hair inorganics can be explained by several factors, such as sex, smoking habit, cosmetic treatment, geographical location, diverse environmental exposure, or different dietary habits [29].

Hair analysis is non-invasive, with easy-to-obtain samples, and reflects a long time or past exposure average, so hair would be a promising matrix of exposure to monitor if the problem of external contamination removal can be overcome [30]. Unfortunately, the question of the origin (internal or external) of the fraction of elements effectively removed by washing is difficult to answer, as the true effects of washing are not yet fully elucidated [17]. On the one hand, the elements characterized by low washing efficiency values $(\mathrm{P}, \mathrm{V}, \mathrm{Cr}, \mathrm{Fe}, \mathrm{Co}, \mathrm{Ag}, \mathrm{Sn}$, and $\mathrm{Sb}$ ) could be strongly bonded with the hair structure and thus perhaps more related to the internal exposure. On the other hand, the majority of the elements being more easily washed (particularly for the spiked samples) could be linked to the hair surface. In most studies, it seems that the analytical method used (ICP-MS principally) does not allow for a precise localization of contamination in hair, and other techniques such as LA-ICP-MS, ToF-SIMS, or SXRF, should be envisaged for the purpose [12, 16, 31, 32]. However, these techniques need more expensive instruments than ICP-MS, which is often found in laboratories, which can be a limitation for biomonitoring.

If hair samples reflect the past exposure averaged over their extent during the period of their growth, there are some limitations in considering hair biomonitoring as a reliable index of chronic exposure principally due to the potential for sample contamination [33]. However, Pozebon [16] underlined in a recent review that hair inorganic analysis can provide important information for evaluation of past contamination from the environment and ways of absorption and transformation by the organism. Regarding this last point, chemical speciation could be enlarged from As and $\mathrm{Hg}$ to other elements [33-35]. Finally, Skröder [36] proposed to limit the relevance of children's hair as exposure biomarkers to only As and Se among 12 elements studied. These elements were apparently not affected by external contamination after washing the samples using Triton X. They also suggested that it would be possible to use specific segments of the hair to assess the exposure or the intake over time or at a certain point of time.

\section{Conclusion}

If the washing step is considered a crucial point for hair inorganic analysis over the past 40 years, no consensus can be found in the literature. With the aim of improving the removal of external contamination of hair samples, a new washing protocol, $\mathrm{TNCl}$, was proposed based on three stages, with two acidic ones, and was less time consuming compared to other methods. This protocol was derived from the TN method [20] and included an extraction stage with nitric acid by adding a supplementary acidic washing stage with hydrochloric acid. Inspired by the practices of metal removal in the environment (e.g., contaminated sediment treatment), the acidic extraction steps are efficient and provide better results than other washing methods based on the use of organic solvents or surfactants. This washing method was tested on spiked and nonspiked hair samples and compared with other existing washing methods after the validation of the analytical procedure (digestion and ICP- 
MS analysis) with certified materials and interlaboratory trials. As expected, the washing method leads to a higher washing efficiency for $\mathrm{Mg}, \mathrm{Ca}, \mathrm{Zn}, \mathrm{Cu}, \mathrm{Mn}, \mathrm{Pb}$, and $\mathrm{Cd}$. For the other elements, $\mathrm{K}$ is easily washable with any methods, $\mathrm{Fe}$ is extracted at $\sim 30-50 \%$, Cr shows different values of washing efficiency depending on the study, and Se is poorly extracted.

Hair analysis was then carried out with the TNCl washing method on 10 hair samples, and the results were compared with three recent studies and one meta-analysis on four comparable studies. For the 18 elements compared, the values were fully coherent with those in the other studies and close to the low value of the ranges of the meta-analysis. These results confirm that based on its efficiency, the $\mathrm{TNCl}$ washing method can be a first step in the assessment of external contamination, at least for the elements strongly ( $\mathrm{Zn}, \mathrm{P}, \mathrm{Fe}, \mathrm{Cu}$, and As) or weakly ( $\mathrm{Na}$, $\mathrm{K}, \mathrm{Pb}, \mathrm{Ba}$, and $\mathrm{V}$ ) bound to hair. These hypotheses should be confirmed and validated more robustly via a larger study, using hair of different types [37], origins, concentration levels, life styles, dietary differences, and environmental exposure conditions. In the case of the use of hair as a biomarker for the biosurveillance of population-based exposures or epidemiological surveillance, a careful pool of samples, proper statistical tools, including repeated and replicated results, and careful quality control have to be considered for to obtain reliable conclusions [16].

Acknowledgements Claude Briens and Françoise Lacroix from Laboratoire d'étude et recherche en environnement et santé (LERES) are gratefully acknowledged for their technical support. Bernard Jegou and Cyril Harpet, who followed the work at its early beginning, must also be thanked. We thank EHESP and Irset (Institut de recherche en santé, environnement et travail)-UMR_S 1085 for supporting the achievement of this research activity.

\section{Compliance with ethical standards}

Conflict of interest The authors declare that they have no conflict of interest.

\section{References}

1. Labat L. La préparation des matrices biologiques pour l'analyse des métaux. Ann Toxicol Anal. 2010;22:81-88.

2. Afridi HI, Gul Kazi T, Brabazon D, Naher S. Association between essential trace and toxic elements in scalp hair samples of smokers rheumatoid arthritis subjects. Sci Total Environ. 2011;412413:93-100.

3. Aleksa K, Liesivuori J, Koren G. Hair as a biomarker of polybrominated diethyl ethers' exposure in infants, children and adults. Toxicol Lett. 2012;210:198-202.
4. Król S, Zabiegała B, Namieśnik J. Human hair as a biomarker of human exposure to persistent organic pollutants (POPs). Tr Anal Chem. 2013;47:84-98.

5. Appenzeller BMR, Tsatsakis AM. Hair analysis for biomonitoring of environmental and occupational exposure to organic pollutants: state of the art, critical review and future needs. Toxicol Lett. 2012;210:119-40.

6. Kempson IM, Lombi E. Hair analysis as a biomonitor for toxicology, disease and health status. Chem Soc Rev. 2011;40:3915-40.

7. Pragst F, Balikova MA. State of the art in hair analysis for detection of drug and alcohol abuse. Clin Chim Acta. 2006;370:17-49.

8. Jeruszka-Bielak M, Brzozowska A. Relationship between nutritional habits and hair calcium levels in young women. Biol Trace Elem Res. 2011;144:63-76.

9. Coelho P, Costa S, Silva S, Walter A, Ranville J, Sousa ACA, et al. Metal(loid) levels in biological matrices from human populations exposed to mining contamination-Panasqueira mine (Portugal). J Toxicol Environ Health. 2012;75:893-908.

10. Olmedo P, Pla A, Hernández AF, López-Guarnido O, Rodrigo L, Gil F. Validation of a method to quantify chromium, cadmium, manganese, nickel and lead in human whole blood, urine, saliva and hair samples by electrothermal atomic absorption spectrometry. Anal Chim Acta. 2010;659:60-67.

11. Martín-Cameán A, Molina-Villalba I, Jos A, Iglesias-Linares A, Solano E, Cameán AM, Gil F. Biomonitorization of chromium. copper. iron manganese and nickel in scalp hair from orthodontic patients by atomic absorption spectrometry. Environ Toxicol Pharmacol. 2014;37:759-71.

12. Limbeck A, Galler P, Bonta M, Bauer G, Nischkauer W, Vanhaecke F. Recent advances in quantitative LA-ICP-MS analysis: challenges and solutions in the life sciences and environmental chemistry. Anal Bioanal Chem. 2015;407:6593-617.

13. Kumakli H, Aja VD, McDaniel K, Mehari TF, Stephenson J, Maple L, et al. Environmental biomonitoring of essential and toxic elements in human scalp hair using accelerated microwaveassisted sample digestion and inductively coupled plasma optical emission spectroscopy. Chemosphere . 2017;174:708-15.

14. Rodrigues JL, Nunes JA, Batista BL, De Souza SS, Barbosa F Jr. A fast method for the determination of 16 elements in hair samples by inductively coupled plasma mass spectrometry (ICP-MS) with tetramethylammonium hydroxide solubilization at room temperature. J Anal At Spectro. 2008;23:992-6.

15. Llorente-Ballesteros MT, Navarro-Serrano I, Izquierdo-Álvarez S. Reference levels of trace elements in hair samples from children and adolescents in Madrid, Spain. J Trace Elem Med Biol. 2016;43:113-20.

16. Pozebon D, Scheffler GL, Dressler VL. Elemental hair analysis: a review of procedures and applications. Anal Chim Acta. 2017 https://doi.org/10.1016/j.aca.2017.09.017.

17. Kempson IM, Skinner WM. A comparison of washing methods for hair mineral analysis: internal versus external effects. Biol Trace Elem Res. 2012;150:10-14.

18. Journal Officiel français $n^{\circ} 182$ 2004. Loi $n^{\circ} 2004-800$ du 6 ao ût 2004 relative à la bioéthique, 2004.

19. Batista BL, Rodrigues JL, Cristina V, Souza O, Barbosa F. A fast ultrasound-assisted extraction procedure for trace elements determination in hair samples by ICP-MS for forensic analysis. Forensic Sci Intern. 2009;192:88-93.

20. Eastman RR, Jursa TP, Benedetti C, Lucchini RG, Smith DR. Hair as a biomarker of environmental manganese exposure. Environ Sci Technol. 2013;47:1629-37.

21. Agence française de normalisation (AFNOR). Norme NF T90210, Qualité de l'eau-Protocole d'évaluation initiale des performances d'une méthode dans un laboratoire. 2009. 
22. Akcil A, Erust C, Ozdemiroglu S, Fonti V, Beolchini F. A review of approaches and techniques used in aquatic contaminated sediments: metal removal and stabilization by chemical and biotechnological processes. J Clean Prod. 2015;86:24-36.

23. Kim KJ, Kim DH, Yoo YC, Baek K. Electrokinetic extraction of heavy metals from dredged marine sediment. Sep Purif Technol. 2011;79:164-9.

24. Borella P, Rovesti S, Caselgrandi E, Bargellini A. Quality control in hair analysis: a systematic study on washing procedures for trace element determinations. Microchim Acta. 1996;123: 271-80.

25. Bujdoš M, Kubová J, Streško V. Problems of selenium fractionation in soils rich in organic matter. Anal Chim Acta. 2000;408:103-9.

26. Mikulewicz M, Chojnacka K, Gedrange T, Górecki H. Reference values of elements in human hair: a systematic review. Environ Toxicol Pharmacol. 2013;36:1077-86.

27. Raposo JC, Navarro P, Sarmiento A, Arribas E, Irazola M, Alonso RM. Analytical proposal for trace element determination in human hair. Application to the Biscay province population, northern Spain. Microchem J. 2014;116:125-34.

28. Skalny AV, Skalnaya MG, Tinkov AA, Serebryansky EP, Demidov VA, Lobanova YN, et al. Reference values of hair toxic trace elements content in occupationally non-exposed Russian population. Environ Toxicol Pharmacol. 2015;40:18-21.

29. Szynkowska MI, Marcinek M, Pawlaczyk A, Albińska J. Human hair analysis in relation to similar environmental and occupational exposure. Environ Toxicol Pharmacol. 2015;40:402-8.

30. Bencko V. Use of human hair as a biomarker in the assessment of exposure to pollutants in occupational and environmental settings. Toxicology. 1995;101:29-39.
31. Kempson IM, Skinner WM. ToF-SIMS analysis of elemental distributions in human hair. Sci Total Environ. 2005;338:213-27.

32. Kempson IM, Skinner WM, Kirkbride KP. Advanced analysis of metal distributions in human hair. Environ Sci Technol. 2006;40:3423-8.

33. Gil F, Hernandez AF. Toxicological importance of human biomonitoring of metallic and metalloid elements in different biological samples. Food Chem Toxico. 2015;80:287-97.

34. Font L, Van der Peijl G, Van Wetten I, Vroon P, Van der Wagt B, Davies G. Strontium and lead isotope ratios in human hair: investigating a potential tool for determining recent human geographical movements. J Anal At Spectrom. 2012;27:719-32.

35. Tipple BJ, Chau T, Chesson LA, Fernandez DP, Ehleringer JR. Isolation of strontium pools and isotope ratios in modern human hair. Anal Chim Acta. 2013;798:64-73.

36. Skröder H, Kippler M, Nermell B, Tofail F, Levi M, Rahman SM, et al. Major limitations in using element concentrations in hair as biomarkers of exposure to toxic and essential trace elements in children. Environ Health Persp. 2017. https://doi.org/10.1289/ EHP1239.

37. Bergdahl IA, Skerfving S. Biomonitoring of lead exposureAlternatives to blood. J Toxicol Environ Health. 2008;71:1235-43.

38. Assarian GS, Oberleas D. Effect of washing procedures on traceelement content of hair. Clin Chem. 1977;23:1771-2.

39. Salmela S, Vuori E, Kilpiö JO. The effect of washing procedures on trace element content of human hair. Anal Chim Acta. 1981;125:131-7.

40. Morton J, Carolan VA, Gardiner PHE. Removal of exogenously bound elements from human hair by various washing procedures and determination by inductively coupled plasma mass spectrometry. Anal Chim Acta. 2002;455:23-34. 